\title{
Phantom Limb Pain: What do we know so far?
}

\author{
Azeem Tariq Malik* \\ Department of Surgery, Aga Khan University, Pakistan
}

Received: October 30, 2017; Published: November 06, 2017

*Corresponding author: Azeem Tariq Malik, Section of Orthopedic Surgery, 11-Tariq Block, New Garden Town, Lahore, Pakistan; Email: azeemtariq94@gmail.com

\section{Mini Review}

The term 'phantom limb pain' was first used by Silas Weir Mitchell, an active surgeon during the $19^{\text {th }}$ century Civil War [1]. However, the concept of pain being perceived by the region of a body that is no longer present was in fact first described way before Silas's time by Ambrose Pare [2] who served as a surgeon in the French military armada in the $16^{\text {th }}$ century. To describe it simply, it refers to either the sensation of a limb still present at the site of an amputation or the presence of intense pain at site of the missing extremity. Often times, both sensations have been reported by amputees in literature. Despite recent literature reporting the incidence of this phenomenon in up to $70-80 \%$ of amputees [3], it still remains a poorly understood and difficult to manage condition. With statistics showing an ever increasing incidence of limb loss occurring in US [4], it becomes of utmost importance that surgeons, anesthesiologists and patients are well aware of this phenomenon prior to conducting amputations for affected extremities. Phantom Limb Pain can consist of a complex of three different entities that can either co-exist or be present separately [5].

i. Phantom Limb: The presence of 'ghost-like' sensations present at the site of amputation. Often time's patients have described these sensations as being akin to their pre-amputated limb so much so that they feel that the limb is still present. These sensations progressively wane over time and are not clinically debilitating as such.

ii. Phantom Pain refers to intense, squeezing, intermittent stabbing pain present at the site of the absent limb. The pain may arise within the first few days after amputation however literature has shown that there is marked variability with some patients even presenting with onset of phantom pain well after several months.

iii. Stump pain is defined as pain localized at the site of amputation. In majority of the patients, it subsides with healing of the wound however persisting pain has been described in up to $5-10 \%$ of the cases.

Several theories have been proposed in an attempt to explain the mechanism of phantom pain. To summarize, it is believed that following amputation neuromas form at the cut end of the nerves.
These neuromas show abnormal and increased activity following mechanical stimulation, resulting in increased pain transmission [6]. Neural plasticity may also play a role in pain transmission as it is a generally accepted belief that modification of NMDA receptors post-amputation contribute to a heightened sensation of pain. It is also believed that the sympathetic nervous system also plays a role in mediation of pain in phantom limb. Studies have shown that post-amputation injections of norepinephrine result in increased pain at the site. This finding paved way to the use of sympatholytics as a mode of treatment for phantom limb pain. In most recent years however it is thought that cortical reorganization plays an important role in pain transmission. It is believed that cortical areas representing the amputated extremity are taken over by surrounding association areas in both the primary somatosensory and motor cortex $[7,8]$.

The treatment of phantom pain is still very vague. A wide variety of treatment modalities consisting of medical and surgical procedures have been used with inconsistent results. Common and important medical treatment methods include the use of TCAs, anticonvulsants, lidocaine (as a sympatholytic), opiods, NMDA receptor anatagonists (to counter-act neural plasticity) and benzodiazepines to name a few. Surgical treatment more or less has now been forgotten and abandoned due to unfavorable results in the general population [8]. Non pharmacological methods have found some interesting results, however these are limited by the low quality of evidence of the studies [9]. One treatment of interest that may be of some benefit is the mirror therapy. The principle of this treatment consists of superimposing a mirrored image of the intact limb onto the missing one. Using reflection of voluntary movements in a mirror performed by the intact limb, it creates a visual illusion of painless movement in the absent limb. It basically tricks the brain to perceive that the limb is actually present and breaks off the sensory-pain pathway. However, a recent systematic review done in 2016 showed that though studies show effectiveness of MT, majority of them are low evidence studies with a small sample size. Keeping this constraint in mind, only a more definitive conclusion can be reached with an appropriately designed randomized control trial with an adequate sample size [10]. 


\section{Conclusion}

In conclusion, the management of this phenomenon will primarily consist of an amalgamation of medical treatments and mirror therapy. In addition, we believe that it is essential to inform that patient and fully explain the phenomenon of phantom limb pain prior to undergoing amputation. This will allow the patients to gain a better understanding of what to expect post-amputation and in the scenario that these phenomena do arise; they are better coped to handle it psychologically and mentally. With future researches catering to investigating a more effective way of managing this common condition, we hope that a more substantial answer can be reached soon.

\section{References}

1. Nathanson M (1988) Phantom limbs as reported by S. Weir Mitchell. Neurology 38(3): 504-505.

2. Weinstein SM (1998) Phantom limb pain and related disorders. Neurol Clin 16(4): 919-936.

3. Dijkstra PU, Geertzen JH, Stewart R, vander Schans CP (2002) Phantom pain and risk factors: a multivariate analysis. J Pain Symptom Manage 24(6): 578-585.
4. Ziegler Graham, K., MacKenzie EJ, Ephraim PL, Travison TG, Brookmeyer $R$ (2008) Estimating the prevalence of limb loss in the United States: 2005 to 2050. Arch Phys Med Rehabil 89(3): 422-429.

5. Nikolajsen L, TS Jensen (2001) Phantom limb pain. Br J Anaesth 87(1): 107-116.

6. Amir R, M Devor (1993) Ongoing activity in neuroma afferents bearing retrograde sprouts. Brain Res 630(1-2): 283-288.

7. Baron RA, Binder, G Wasner (2010) Neuropathic pain: diagnosis, pathophysiological mechanisms, and treatment. Lancet Neurol 9(8): 807-819.

8. Subedi B, GT Grossberg (2011) Phantom limb pain: mechanisms and treatment approaches. Pain Res Treat 2011: 864605.

9. Batsford S, CG Ryan, DJ Martin (2017) Non-pharmacological conservative therapy for phantom limb pain: A systematic review of randomized controlled trials. Physiother Theory Pract 33(3): 173-183.

10. Barbin J, Seetha V, Casillas JM, Paysant J, Pérennou D (2016) The effects of mirror therapy on pain and motor control of phantom limb in amputees: A systematic review. Ann Phys Rehabil Med 59(4): 270-275.

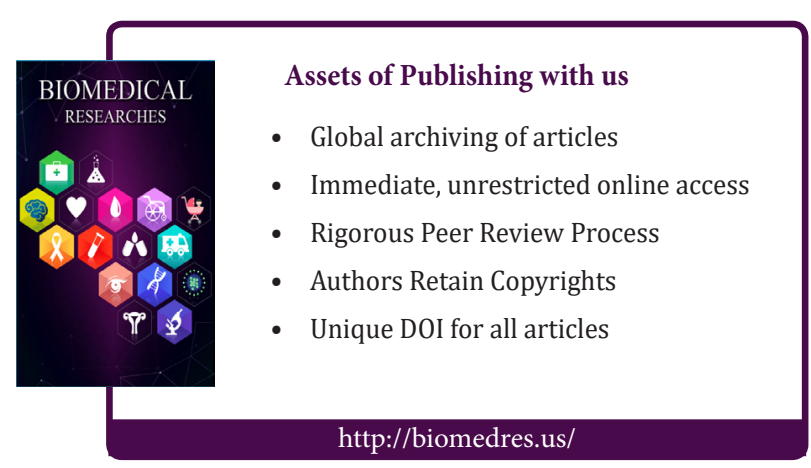

